\title{
The Nexus Between Fatigue Indices and Coping Strategies in Sports Among Oyo State Special Athletes
}

\author{
Adebayo Francis Komolafe, PhD \\ Department of Special Education, University of Ibadan, Nigeria
}

Doi: 10.19044/esj.2018.v14n1p151 URL:http://dx.doi.org/10.19044/esj.2018.v14n1p151

\begin{abstract}
Disability sports have acquired an indispensable status in the life of many nations and the special athlete as a whole. Special athletes are exposed to a number of intense physical and psychosocial activities and they needed to make use of a set of cognitive and behavioural strategies in order to cope with these challenges and related fatigue. Hitherto, previous studies had focused largely on adaptive sports and effects of sporting activities on persons with disability without establishing a link between disabled athlete's use of coping strategies and their achievement motivation. Therefore, it is on this premise that this study harps on the relationship between fatigue indices and coping strategies among Oyo State special athletes. Descriptive survey design using purposive sampling technique was employed. Participants of the study include all the registered special athletes in Oyo State comprising of one hundred and twenty three (123) athletes. Two standardized instruments, thus, Modified fatigue impact scale $(\mathrm{r}=0.384)$ and Athletic coping skills inventory $(\mathrm{r}=0.514)$ were both employed. Altogether, five hypotheses were tested at 0.05 significant level, and parametric statistics, Pearsons Product moment correlation, and multiple regression analysis were used to analyse the data. Findings revealed significant effect of two independent variables on the dependent variable: cognitive style $(\beta=0.294, \quad \mathrm{r}=0.514, \mathrm{P}<0.05)$ and psychosocial factors $(\beta=0.236, r=0.499, \mathrm{P}<0.05)$, while modified fatigue impact has no significant relative effect on coping strategies. The composite effect of independent variables (Modified Fatigue Impact, Cognitive style and Psychosocial Factor) on Athletic coping skills was significant $\left(_{(\mathrm{F}(3,119)}=166.777\right)$ and about $30 \%$ of the variation was accounted for by the independent variables as explained by the adjusted $\mathrm{R}$ square. It is therefore recommended that the relationship between fatigue indices and coping strategies is high and the higher the individuals rated their coping with fatigue caused by their disabilities, the lower they scored on fatigue experiences. The more they used coping strategies, the more efficient they coped with fatigue.
\end{abstract}


Keywords: $\quad$ Fatigue, Coping Strategies, Physical Disabilities, Disables and Sport

\section{Introduction}

Disability sports especially at the elite level has acquired an indispensable status in the life of many nations and special athletes as a whole. The entertaining and business potentialities of sports cut across ages, sexes races, religious, cultural and socio-economic discriminations, able bodied and disabled (Lannem, Serenson, Lidal, Hjeltnees, 2009). Sports reflect an avenue for inculcating in the special athletes physical habits that would result in the attainment of higher character.

Sports, the world over, is a vehicle for recreation, mobilization, social integration and fostering of national and international understanding. Developing the human mind and physical wellbeing are two incontrovertible contributions of sports to human civilization. Without doubt, these two (developing human mind and physical well being) represent the critical forces, for the survival and rehabilitation of the persons with disability.

Sporting activities require a lot of energy to train everyday to keep in form. Special athletes train, most times from morning to evening. Their awkward movement interference of artificial on their bodies with their natural body, cause fatigue. Therefore, resting during the time of activities will occur.

A great deal of research work has been done to analyse the special athletes' fatigue and ways by which the persons with disabilities cope. For instance, Allianz, (2012); Richardson, Anderson and Morris (2008) all worked on reduction of fatigue. Lannem, et al., (2009) explained that when coping strategies are identified and put into practice, they are very useful in making disability sports an interesting one. A study conducted by Smith and Christiensen (1994) examined the influence of coachability, coping with adversity, concentration, confidence/achievement motivation, goal setting/mental preparation, peaking under pressure and freedom from worry as the antidotes to fatigue and disabled are at the highest benefit. Elite special athletes are exposed to a number of intense physical and psychosocial demands and they use a set of cognitive and behavioural strategies in order to cope with those challenges and related fatigue (Crocker, Alderman and Smith 1988; Gould, Finch and Jackson, 1993).

There is a growing body of literature, empirical and theoretical, that has investigated the effects of exercise on physical disability. Exercise is the "training of the body to improve its function and enhance its fitness (Biddle, 2001). It has many benefits. physically fit individuals are thought to be able to engage in everyday activities without feeling tired or exhausted and better able to withstand disease, infection and deterioration. However, to enjoy its benefits, people need to exercise with sufficient intensity for 30 minutes five 
times per week (British Heart Foundations 2013). Although, there is no conclusive evidence that exercise prolongs life, many epidemiological studies show that regular exercise is associated with reduced risk of many lifethreatening illnesses (Odejide and Olatawuram, 2000).

The claim that exercise therapy improves health and well being has long history. There is widespread support for a positive and lasting relationship between participation in regular exercise and various indices of coping in fatigue. Several consensus documents and reviews have been published in this field (Abiodun, 2000; Biddle, 2001; Craft and Lauders, 2008).

Disability is any physical or mental condition that limits a person's moments, senses or activities. It occurs when a structure or organ of the body is damaged and there is restriction or inability to perform the functions requires of the organ (Komolafe, 2016). Disability could be caused by different factors among which are prenatal (before birth), including heredity, infectious diseases, blood incompatibility, malformation, drugs and mother's nutrition. Some of the perinatal (during birth) causes including, but not limited to premature, prolonged labour, birth injuries and anoxia. For some postnatal (after birth) causes are accident, diseases, poliomyelitis, measles and drugs. Disability covers a wide range of areas. Smith (2007) identified the 14 special Education categories as called out by the United States of America (USA), Federal Government as: Autism Spectrum Disorders, Deaf-blindness, Deafness, Developmental Delay, Emotional Disturbances, Hearing Impairment, Mental Retardation (now Intellectual disability), Multiple Disabilities. Others are speech or language impairment Traumatic Brain Injury and Visual Impairment. It is worthy to note that persons with disabilities can participate in sporting activities. Disability sports have grown from a small gathering to become one of the largest international sporting events. For instance, Komolafe (2016) submitted that over the years, great impetus is given to the sporting activities of persons with disability. $\mathrm{He}$ submitted further that sports for persons with disability are deliberately encouraged within national boundaries. Within this context, the Federal Government of Nigeria established in 1987, the Special Sports Federation of Nigeria (SSFN) formerly, Nigeria Sports Association for the Disabled (NSAD). It (SSFN) enjoys recognition and indeed affiliation to relevant international paralympic committee (IPC), International Sports Organisation for the Disable (ISON), International Blind Sports Association (IBSA), International Sports Federation for Persons with Mental Handicap Intellectual Disability (INAS-FMH), General Palsy International Sports and Recreation Association, African Sport Confederation for Disabled just to mention, but few. 
Given the wide variety of disabilities, there are several categories in which the athletes compete. The allowable disabilities are broken down into six broad categories. The categories are computee, cerebral palsy, intellectual disability, wheel chair users and persons with visual impairment. Others are athletes with disabilities that do not fall into the other five categories; these include dwarfism, multiple sclerosis and congenital disorders (Ryan, 1995).

The disability sports comprise all the sport contested in the summer and Winter Disability Games. As of 2012, the summer disability sports include 21 sports and about 500 events. The winter disabled sports include 5 sports and disciplines and about 64 events (SSFN, 2014). In recent years, lots of laurels have been won at international levels by the special atheletes that represented the country (Nigeria) through SSFR. In the year 2000 for instance, 13 medals were won at the Paralympic Games. Also, in the year 2010, 1 medal was won at the Commonwealth Games. However, reverse were the cases in the years 2012 and 2013 as special atheletes that participated at the Paralympic Games in both South Korea and Turkey came home with no medal (SSFR, 2014).

The main thrust of this discourse is that fatigue may easily be experienced by persons with disabilities during these sporting activities. When there is fatigue, there will be overwhelming sense of tiredness, lack of energy and often, a feeling of total exhaustion (Herlofson and Larson, 2002). In sport, fatigue is the onset of a condition of organic and functional exhaustion involving a drop in an athlete's ability to perform which may occur either during an individual competition or during the course of long and intensive training schedules or activities involving competition phases separated by short intervals (Dal Monte, Faina, and Mirri 2002). When an individual experiences fatigue, he/she may not want to continue with the activity any longer. Ursing and Erikson (2012) posited that fatigue is a lack of physical and or mental energy. This energy loss is interfered into the ability of the individual during an activity especially, sports. This is likely to be the case of athletes with disabilities. Fatigue limits functional activities or quality of life. Fatigue is an increased weakness with exercise or as the day progresses as an abnormal constant and persistent sense of tiredness or as a fatigable weakness exacerbated by activity. Fatigue can be chronic persistent and acute. It is chronic persistent when it is present for any amount of time on $50 \%$ of the days for more than 6 weeks. While acute fatigue is when there is a significant increase in feeling during the previous 6 weeks (Collins, 1997). It must be noted that, persons traumatized by the disabilities are already basking in the physical and emotional trauma as imposed in him/her by disabilities. One will not be surprised that when the same set of persons engage in sporting activities, fatigue may be envisaged. If fatigue sets in, there are some ways in 
which individuals can manage it. Managing fatigue in this study is refer to as coping strategies.

Coping strategies can be explained as any changes in thoughts or behaviours that are made to manage the perceived demands of a situation (Lazarus and Folkman, 1987). Coping lies at the very heart of competitive sport. The way in which performers perceive the challenges, success and failure provides the human story that brings spectators to modern professional sport.

Coping has traditionally been studied using two major approaches: a style approach and a process situation approach (Carver, Scheier and Weintraub, 1989; Lazarus, 1993). The style approach claimed that certain personality characteristics can predict how an individual copes when facing adversity (Carver, 1987). However, the process oriented approach to coping according to Lazarus and Folkman (1987) posited that it is concerned with an individual's actual thoughts and behaviour. It focuses on the individual's thoughts and behaviour within a specific context. The most significant limitations is that process approach measures do not consider the whole person, who has certain belief systems, social connections and a particular goal hierarchy.

With measuring coping, both approaches are important. Lazarus (1999) was of the opinion that these perspectives complement each other and neither perspective can by itself provide enough understanding of emotion and adaptation within the coping process.

Statement of the Problem

Persons with disabilities in some societies are considered dependent and viewed as incapable. Observation is that about $85 \%$ of the disabled athletes are not very at ease when they are in motion. Sometimes, some will have to stop their actions to rest for some moments. This could be due to the awkward posture, weight of the artificial limbs or any part of the body fixed on the individual. Also, there could be pain due to the interference of the artificial with the natural body. Research on athletes' coping strategies as well as their achievement motivation in sport has received a lot of attention in sport psychology (Richards, 2004 and Roberts, 2002). Research on coping in sport started with trying to clarify which coping responses athletes use across various sports settings. For example, Gould et al (1993). However, only a few studies have examined the link between disabled athlete's use of coping strategies and their achievement motivation. This study, therefore, investigated the relationship between fatigue indices and coping strategies in sports among Oyo State special athletes.

Hypotheses

The following null hypotheses were tested at 0.05 level of significance. 
- $\quad$ There is no significant relationship between Athletic Coping Skills and Modified Fatigue Impact in sports and Oyo State special athletes;

- There is no significant relationship between Athletic Coping Skills and Cognitive Style in sports and Oyo State special athletes;

- There is no significant relationship between Athletic Coping Skills and Psycho-Social Factors in sports and Oyo State special athletes

- There is no significant relative effect of Independent variables(Modified Fatigue Impact, Cognitive Style and Psycho-Social Factors on Athletic Coping Skills among Oyo State special athletes.

- There will be no significant joint effect of Independent variables(Modified Fatigue Impact, Cognitive Style and Psycho-Social Factors on Athletic Coping Skills among Oyo State special athletes.

\section{Method}

\section{Participants}

The participants in this study were 123 registered special athletes from 7 disabilities sports zones in Oyo State. These are: Ibadan City zone (21), Ibadan less city zone (15) Oyo zone (36), Ogbomoso zone (12), Saki zone (6) Ibarapa zone (12 and Okeho zone (6). These were purposively selected. Their mean age $($ mean $=23.62$; SD 9.4).

\section{Procedure for Data Collection}

The ethical approval to conduct the study was obtained from the appropriate authority, while the consent of the special athletes to participate in the research were sought through the consent form filled and signed by the athlete that volunteered to participate in the research. The content of the instrument were explained to them before the data was collected.

\section{Measures}

Two standardized instruments were used for data collection. These instruments are: Athletic coping skills inventory and modified fatigue impact scale. The first instrument was the Athletic coping skills Inventory (A.C.S.I.) developed by Smith and Christensen (1994). This instrument contains 28 items of four point rating Likert format ranging from 0 to 3 . Thus, $0=$ Almost Never, $1=$ sometimes, $2=$ Often, and $3=$ Almost Always. It has seven subscales ranging from: coping with Adversity, coach ability, concentration, confidence and Achievement Motivations, Good setting and Mental preparation, Peaking under pressure, and freedom from worry. This instrument has adequate psychometric properties with Cronbach alpha values of 0.70 (Smith and Christensen, 1994) and confirmatory reliability coefficient of 0.76 . 
The second instrument was the Modified Fatigue Impact Scale (M.F.I.S.) developed by Kos, Dupertail, D'hooghe, Nagels and Kerckhofs (2003). This instrument contains 21 -items of five point rating likert format ranging from 0 to 4 . Thus, $0=$ Never, $1=$ Rarely, $2=$ Sometimes, $3=$ often, and $4=$ Almost Always. Items on MFIS can be aggregated into 3 subscales (physical, cognitive and psychosocial) as well as into total MFIS score. The psychometric properties are Cronbach alpha values of 0.92 (Physical subscale), 0.88 (cognitive subscale), and 0.92 (psychosocial subscale) respectively (Kos, et al., 2003).

\section{Data Analysis}

The descriptive survey design of correlation was used because the variables involved in this study were not manipulated. Descriptive statistics of percentage and mean were used where appropriate, the parametric statistical of correlation and multiple regression models were also used for the relationship and prediction.

\section{Results}

$\mathrm{Ho}_{1}$ : There is no significant relationship between Athletic coping skills (A.C.S) and Modified fatigue Impact (M.F.I).

Table 1: Correlation Table showing relationship between Athletic coping skills and Modified Fatigue Impact

\begin{tabular}{|c|c|c|c|c|c|c|}
\hline Variables & Mean & Std. Dev & $\mathrm{N}$ & $\mathrm{R}$ & $\mathrm{P}$ & Remarks \\
\hline $\begin{array}{c}\text { Athletic coping } \\
\text { skills }\end{array}$ & 61.1382 & 9.3459 & \multirow{2}{*}{123} & $.384 * *$ & .000 & Sig. \\
\cline { 1 - 3 } $\begin{array}{c}\text { Modified Fatigue } \\
\text { Impact }\end{array}$ & 15.2114 & 5.6500 & & & \\
\hline \multicolumn{7}{|c}{$* *$ significant at $0.05 \%$} \\
\end{tabular}

Table 1 above shows that there exist a significant relationship between Athletic coping skills and Modified Fatigue Impact $\left(\mathrm{r}=.384^{* *}, \mathrm{P}<0.05\right)$. Thus, the null hypothesis is rejected.

$\mathrm{Ho}_{2}$ : There is no significant relationship between Athletic coping skills and cognitive style.

Table 2: Correlation Table showing the nature of relationship between Athletic coping skills and cognitive style.

\begin{tabular}{|c|c|c|c|c|c|c|}
\hline Variables & Mean & Std. Dev & $\mathrm{N}$ & $\mathrm{R}$ & $\mathrm{P}$ & Remarks \\
\hline $\begin{array}{l}\text { Athletic coping } \\
\text { skills }\end{array}$ & 61.1382 & 9.3459 & \multirow[t]{2}{*}{123} & \multirow[t]{2}{*}{$.514 * *$} & \multirow[t]{2}{*}{.000 } & \multirow{2}{*}{ Sig. } \\
\hline Cognitive style & 13.7886 & 5.1379 & & & & \\
\hline
\end{tabular}


The table above reveals that there was significant relationship between Athletic coping skills and cognitive style $\left(\mathrm{r}=0.514^{* *}, \mathrm{P}<0.05\right)$. The null hypothesis is thereby rejected.

$\mathrm{Ho}_{3}$ : There is no significant relationship between Athletic coping skills and psychosocial factors.

Table 3: Correlation showing relationship between Athletic coping skills and psychosocial factors.

\begin{tabular}{|c|c|c|c|c|c|c|}
\hline Variables & Mean & Std. Dev & N & R & P & Remarks \\
\hline Athletic coping skills & 61.1382 & 9.3459 & \multirow{2}{*}{123} & \multirow{2}{*}{$.499 * *$} & \multirow{2}{*}{.000} & Sig. \\
\cline { 1 - 3 } & & & & & \\
\hline Psychosocial factors & 02.9919 & 1.5550 & & & & \\
\hline
\end{tabular}

It is shown in the table above that there was significant relationship between Athletic coping skills and psychosocial factor $\left(\mathrm{r}=0.499^{* *}, \mathrm{p}<0.05\right)$. Thus, the null hypothesis is rejected.

Ho4: There are no relative effects of independent variables (modified Fatigue Impact, cognitive style and psychosocial factors) on Athletic coping skills.

Table 4: Multiple Regression showing relative effects independent variables (Modified

Fatigue Impact, Cognitive style and Psychosocial Factors) on Athletic Coping skills.

\begin{tabular}{|c|c|c|c|c|c|}
\hline Model & \multicolumn{2}{|c|}{$\begin{array}{c}\text { Unstandardized } \\
\text { Coefficient }\end{array}$} & $\begin{array}{c}\text { Standardized } \\
\text { coefficient }\end{array}$ & T & Sig. \\
\hline & $\mathrm{B}$ & Std. Error & & & \\
\hline Constant & 47.638 & 2.315 & & 25.500 & .000 \\
\hline Modified fatigue impact & .121 & .164 & .073 & .741 & .460 \\
\hline Cognitive style & .536 & .222 & .294 & 2.416 & 0.017 \\
\hline Psychosocial factor & 1.425 & .726 & .236 & 1.964 & .052 \\
\hline
\end{tabular}

Result of table 4 reveals that modified fatigue Impact does not have effect on the dependent variable, that is athletic coping skills $(\beta=0.073$, $\mathrm{P}>0.05)$. On the other hand, both cognitive style and psychosocial factors were found to have significant relative effects of the dependent variables cognitive style $(\beta=0.294, \mathrm{P}<0.05)$ psychosocial factor $(\beta=0.236, \mathrm{P}<0.05)$.

Ho5: There is no joint significant effect of independent variables (Modified Fatigue Impact, Psychosocial Factors and Cognitive style) on Athletic Coping skills.

Table 5: Joint effect of Independent Variables (Modified Fatigue Impact, Psychosocial Factor and Cognitive style) on Athletic coping skills

\begin{tabular}{|c|c|c|c|c|c|}
\hline Model & Sum of square & Df & Mean square & $\mathrm{F}$ & Sig. \\
\hline Regression & 3187.675 & 3 & 1062.558 & 16.777 & .000 \\
Residual & 7536.975 & 119 & 63.336 & & \\
Total & 10724.650 & 122 & & & \\
\hline
\end{tabular}

$\mathrm{R}=0.545, \mathrm{R}^{2}=0.297, \operatorname{Adj} \mathrm{R}^{2}=0.280$ 
Results in table 5 reveals that there is significant joint effect of the independent variables (Modified Fatigue Impact, Psychosocial factor and cognitive style) on Athletic coping skills $(\mathrm{F}(3,119)=16.777$. In investigating the goodness of fit of this result, about $28 \%$ of the variation was accounted for by the independent variables as reported by the adjusted R-square.

\section{Discussion}

Exercise is the training of the body to improve its functions and enhance its fitness (Biddle, 2001). It has many benefits. physically fit individuals are thought to be able to engage in everyday activities without feeling tired or exhausted and better able to withstand disease, infection and any form of deterioration. The findings in this study shows a significant result justifying the assertion that there is significant relationship between physical fatigue indices and coping strategies in sports, among Oyo State athletes. Fatigue brings about total exhaustion, lack of energy, and overwhelming sense of tiredness which will be managed by using desired coping strategies (Chaudhuri and Behan, 2004).

Ursin and Erikson (2004) in their study on coping strategies, view that if an individual expect to handle the stressor/stimuli in a positive way, the arousal will be short and no harmful health consequences will occur. If, however, the individual do not expects to be able to handle that which causes fatigue, the arousal will persist and may result in hopelessness. Without coping strategies, fatigue fullness will reduce the psychological and physiological activities of an individual. It is on this premise that Kos et al. (2003) developed the modified fatigue impact scale to measure the impact of fatigue on a person's activities.

Our findings which shows positive relationship between cognitive style indexes and coping strategies lend credence to Lazarus (2000), which emphasized that coping is a cognitive analogue of action tendencies. The general non-specific fatigue responses can be viewed as an alarm to raise neurophysiologic activation to a higher level. The alarm is activated when something is missing or unexpected and which triggers cognition in the body. Whether the stressor is edifying or frightening, dependents upon the individual assessment of the situation.

Findings of this study also show a positively significant relationship between psychosocial fatigue indexes and coping strategies, among Oyo State special athletes. Richardson Anderson and Morris (2008) opined in their study that psychosocial factor such as good mood, positive emotions and acceptance are avenues for escape from fatigue. When positive coping strategies are adopted, fatigueable environment shall be ruled off in the lives of people with physical disabilities. 
It was also revealed in our findings that there is significant relative on Oyo State special athletes. Lazarus and Folkman (1987), argued in their study that there is high cognitive value among the cerebral palsy athletes, even with their level of fatigue and stressful environment. Psychosocial and psychomotor abilities still remain the same. The higher the individuals rated their coping strategies caused by their disabilities, the lower they scored on fatigue experiences (Deci and Ryne, 1995).

\section{Conclusion}

The objectives of this study can be summarized into: (a) exploring the relationship between fatigue indices and coping strategies; (b) whether or not special athletes use coping strategies to treat fatigue and (c) the level of fatigue the special athletes of Oyo State experience. The author, through the work, affirm the relationship between physical fatigue indices and coping strategies. Also, significant relationship existed between cognitive fatigue indices and coping strategies. Also, significant relationship existed between cognitive fatigue indices and coping strategies. There was significant relationship between psychosocial fatigue indices and coping strategies. The special athletes endeavoured to do well with the level of disabilities they have. It is important to equally note that, their cognitive values remain the source. The higher the individuals rated their coping with fatigue caused by their disability, the lower they scored on both fatigue coping strategies scales.

\section{Recommendations}

Special athletes experience some levels of fatigue from time to time. If adequate coping strategies are adopted, fatigue could be eliminated. Therefore, based on the findings, the author recommends that:

a) Goals should be set by the special athletes before commencement of play or competition;

b) The special athletes should worry less so that they can be freed from worries;

c) Athletes should maintain stable emotion regardless of situation in the game and

d) Driving services to ease troubles accompanying travelling to and from sport facilities should be provided for. This will ameliorate fatigue.

\section{References:}

1. Abiodun, O.A. 2000. Mental health and primary care in Africa East Africa. M.ed. J., 2000. American Psychiatric Association. 1994. Diagnostic and statistical manual of mental disorders. Washington, DC. American Psychiatric Association. 
2. Biddle, S. 2001. Exercise and depression. British Medical Journal. Retrieved on 10/10/2013 from: http://btnj.bmjjjournals.com/cgi/eletters/311/7289/

3. British Heart Foundation Health Promotion Research Group. 2013. Estimates of the primary and secondary care costs attributable to physical inactivity for PCTs across England, Commissioned by Sport England.

4. Carver C.S. 1998. Resilience and thriving: Issues, models and linkages. Journal of Social Issues.1998;54:245-266.

5. Carver, C. S., Scheier, M. F., and Weintraub, J. K. 1989. Assessing coping strategies: A theoretically based approach. Journal of Personality and Social Psychology, 56 (2), 267-283.

6. Chaudhuri, A. and Behan, P. O. 2004. Fatigue in neurological disorders. M Lancet.

7. Collins, D. 1997. Conference Report, National disability Sport Conference. London: Kings fund centre.

8. Craft, L.L. and Landers, D.M. 1998. The effects of exercise on clinical depression resulting from mental illness: a meta-analysis. J Sport Exercise Psychology 20:339-357

9. Crocker, P. R., Alderman, R. B., and Smith, F. M. 1988. Cognitiveaffective stress management training with high performance youth volleyball players: Effects on affect, cognition, and performance. Journal of Sport and Exercise Psychology, 10, 448-460.

10. Dal Monte, A., Faina,M. and Mirri, G. 2002. Fatigue and sport: Institute of Sports Science, Italian National Olympic Committee, Rome, Italy, Functional Neurology 17(1): 7-10

11. Deci, E. and Ryne, R., 1995. Human Autonomy: The basis for true self-esteem. In. Kemis (Eds.) Efficacy, Agencies and self esteem. New York. Plenum.

12. Gould, D. Finch, L. M., and Jackson, S. A., 1993. Coping strategies used by national champion figure skaters. Research Quarterly for Exercise and Sport.

13. Gould, D., Eklund, R. C., and Jackson, S. A. 1993. Coping strategies used by more or less successful U.S. Olympic wrestlers. Research Quarterly for Exercise and Sport, 64, 83-93.

14. Herlofson, K. and Larson, J. P. 2000. Measuring fatigue in patients with Parkinson's Disease. The fatigue severity scale. European Journal of Neviology.

15. Kennedy, P., Lude, P., Elfstrom, M. L., and Smithson, E. F. 2011. Psychological contributions to functional independence: a longitudinal investigation of spinal cord injury rehabilitation, Archives of Physical Medicine and Rehabilitation. 
16. Komolafe, A. F. 2016. Sport as a veritable tool for social Integration of persons with disability. A paper delivered at the conference organised by NETWORK FOR Health, Education and Welfare of Special people, Ibadan 29 April.

17. Kos, M., Duportail, M., D'hooghe, M.B. Nagels, G. and Kerckhofs, E. (2003) Multidisciplinary fatigue management programme in multiple sclerosis: a randomized clinical trial," Multiple Sclerosis, vol. 13, no. 8, pp. 996-1003

18. Lannem, A. M., and Sereson, M. Lidal, I. B., and Hjelnes, N. 2010. Perceptions of exercise mastery in persons with complete spinal cord injury (SCI). Submitted to Journal of rehabilitation Medicine.

19. Lannem, A. M., Serenson, M., Lidal, I.K.B., and Hjeltnes, N. 2009. Incomplete spinal cord injury, exercise and life satisfaction.

20. Lazarus R.S. 1993. From psychological stress to the emotions: A history of changing outlooks. Annual Review of Psychology; 44:1-21. [PubMed]

21. Lazarus, R. S. and Folkman, S. 1987. Transactional theory and research on emotions and coping, European Journal of Personality.

22. Lazarus, R. S., and Folkman, S. 1984. Stress, appraisal, and coping. New York: Springer.

23. Lazarus, R.S. 2000. Cognitive-motivational-relational theory of emotion. In Y.L. Hanin (Ed), Emotion in sports (pp.39-63). Champaign, IL: Human Kinetics

24. Richard, K. 2004. Achievement Motivation among Asian Players" AMASS Multilateral Research Journal, 2(2), pp.7-9.

25. Richardson S, Anderson M, and Morris T. 2008. Overtraining Athletes: Personal Journeys in Sport. Champaign (IL): Human Kinetics; p. 15-46

26. Robert G. C. 2007. Achievement Motivation in sports. Department of Physical Education. University of Ilinous.

27. Ryan, N. 1995. The competitive delivery of social services: implications for program implementation, Australian Journal of Public Administration, 54, 3, 353-64.

28. Smith, D. D. 2007. Introduction to special Education: Making a difference. Boston. Allyn and Bacon.

29. Smith, R. E., and Christensen, D. S. 1994. Psychological skills as predictors of performance and survival in professional baseball. Journal of Sport and Exercise Psychology, 17, 399-415.

30. Special Sports Federation of Nigeria, 2014. A Monograph

31. Ursin, H., and Erikson, H. R. (2004). The cognitive activation theory of Stress. Psychoneuroen docrinology. 
32. Ursin, H., and Erikson, H. R. 2012. Cognitive activation theory of stress (CATS) Neuroscience behavioural Reviews. 